Original article

\title{
The effects of Orem's self-care model on the nutrition status and fatigue of colorectal cancer patients
}

\author{
Saba Karimi ${ }^{1}$, Zohreh Vanaki ${ }^{*}$, Homayoon Bashiri ${ }^{3}$, Seyed Abdolmotalab Hassani ${ }^{4}$
}

(Received: 23 Apr 2016; Accepted: 6 Jun 2016)

\begin{abstract}
Background and Purpose: Colorectal cancer (CRC) is one of the most highly prevalent and life-threatening digestive tract cancers. $\mathrm{CRC}$ and its treatment are associated with numerous complications in the patients. Orem's self-care model is a theory on clinical improvement and reducing fatigue in patients with CRC. This study aimed to investigate the effects of Orem's self-care theory on the nutrition status and fatigue of CRC patients.

Methods: This quasi-experimental study was conducted on 70 patients diagnosed with CRC in the teaching hospital of Imam Reza in Kermanshah, Iran in 2014. Samples were randomly divided into two groups of experimental and control. Data were collected using the food frequency questionnaire (FFQ) and Brief Fatigue Inventory (BFI). After data collection, a self-care training program was implemented based on Orem's self-care theory.

Results: Self-care training intervention in the experimental group improved the consumption patterns of fruits $(P=0.002)$, vegetables $(P=0.001)$, and dairy products $(P=0.001)$. Moreover, general fatigue of CRC patients in the experimental group decreased after the intervention $(P=0.0001)$.

Conclusion: According to the results of this study, Orem's self-care model could reduce the clinical symptoms and fatigue of patients with CRC. Therefore, it is recommended that this model be applied to enhance the self-care behaviors and clinical conditions of CRC patients.
\end{abstract}

Keywords: Colorectal cancer, Fatigue, Nutrition, Orem's model, Self-care

\section{Introduction}

Cancer is one of the leading causes of mortality in developed and developing countries, including Iran. Prevalence rate of cancer has been reported to be on the rise, and considerable healthcare resources are allocated to the management and treatment of this chronic disease (1).

In recent years, lifestyle changes and urbanism have resulted in the increased prevalence of different cancer types, especially digestive system cancers $(2,3)$. Colorectal cancer is the second most important cause of cancer deaths, as well as the third and second most prevalent cancer type among men and women, respectively $(4,5)$.

Considering that digestive system cancers account for $38 \%$ of all cancers and $44.4 \%$ of cancer deaths, they are reported as the most prevalent caner types in Iran $(2,3)$. Consumption of foods rich in animal fat, insufficient dietary fiber intake (e.g., fruits,

\footnotetext{
${ }^{1}$ Internal and Surgical Nursing, Tarbiat Modares University of Medical Sciences, Tehran, Iran

${ }^{2,{ }^{*}}$ Corresponding author: Tarbiat Modares University of Medical Sciences, Tehran, Iran. Email: vanakiz@gmail.com

${ }^{3}$ Imam Reza Hospital, Kermanshah University of Medical Sciences (KUMS), Kermanshah, Iran

${ }^{4}$ Internal and Surgical Nursing, Amol University of Medical Sciences, Amol, Iran
} 
vegetables, wheat husk), and inadequate physical activity contribute to the higher prevalence of cancer $(6,7)$.

Colorectal cancer (CRC) is among the most significant causes of cancer-related deaths across the world. According to statistics, 1.2 million patients are diagnosed with $\mathrm{CRC}$, with the mortality rate estimated at 600,000 cases. Furthermore, CRC is the second most common cause of cancer deaths in the United States and other developed countries despite remarkable advancement in disease diagnosis, surgical procedures, and chemotherapy (8). CRC is a chronic disease associated with various symptoms, such as fatigue, lethargy, loss of appetite, anemia, and nutritional disorders.

Current treatments of CRC have been shown to induce complications such as nausea and vomiting, alopecia and stomatitis, which adversely affect the quality of life of the patients $(9,10)$. Fatigue is one of the most frequent and debilitating complications of CRC and its treatment, which is reported by $70-100 \%$ of the patients. Fatigue could be caused by the disease or its treatments. In many CRC patients, fatigue might be so intense that the patient would not be able to perform daily tasks without intervention (11).

Since CRC is a chronic disease associated with numerous treatment complications, self-care abilities play a pivotal role in enhancing the quality of life of the patients. Orem's theory is one of the key theories for the improvement of self-care abilities, which argues that health of an individual could be maintained through self-care. Evidently, self-care behaviors will ultimately bring about a sense of health in the individual $(12,13)$.

Similar to other nursing models, Orem's theory emphasizes on facilitating the role of nurses as the major source of change in the care process (14). Considering the complications and problems of cancer patients, this self-care model is strongly recommended to lead the patient toward self-care behaviors through reinforcing their knowledge, attitudes, and skills, which are based on the medical needs of patients.

According to the literature, Orem's self-care theory has the potential to be used for other chronic diseases, such as peritoneal hemodialysis and heart failure $(15,16)$. In a study entitled "Effects of exercise on the improvement of performance, fatigue, and quality of sleep in patients with colorectal cancer", Chevilan et al. (2013) Applying this model to reduce fatigue in CRC patients and concluded that the level of fatigue decreased in patients of the experimental group (17).

In another study, Zarief Yegane et al. (2009) assessed the nutritional status of cancer patients during chemotherapy, The results of this study showed that patients with gastrointestinal cancer and lungs are in an advanced stage more than any other cancer are malnourished (18).

Extensive research has been conducted regarding the promotion of self-care behaviors and nutrition status, as well as the improvement of fatigue, in CRC patients. In this context, nurses play a critical role in instructing cancer patients on selfcare behaviors. Sufficient self-care abilities could reduce the costs of healthcare services and repeated hospitalization.

This study aimed to evaluate the effects of Orem's self-care model on the nutrition status and fatigue of CRC patients.

\section{Materials and Methods}

This quasi-experimental study was conducted on 70 patients diagnosed with $\mathrm{CRC}$, who were hospitalized in Imam Reza Hospital of Kermanshah, Iran in 2014. Participants were selected via random sampling and divided into two groups of experimental and control.

Inclusion criteria of the study were as follows: 1 ) age range of 40-70 years (male and female); 2) medical record of at least one surgery; 3 ) disease diagnosis within the past year and 4) ability of at least one family member to participate in the educational intervention and accompany the patient throughout healthcare stages. The only exclusion criterion was attending other educational courses held by Imam Reza Medical Educational Center. Sample size of the study was determined using the sample size formula, as obtained through literature review (19), and Altman's nomogram $(\alpha=\% 5, \beta=0.1$, test power $=0.90 \%$ ). 


\section{Applied questionnaires}

Data collection tools included the food frequency questionnaire (FFQ) and Brief Fatigue Inventory (BFI). FFQ is the most reliable instrument to evaluate dietary patterns and classify individuals based on nutrition status to determine the amount of nutrient intake. FFQ consists of 147 items on different food groups, including bread and cereals, proteins, fruits and vegetables, and dairy products. Reliability and validity of this questionnaire have been confirmed in previous studies $(19,20)$. In addition, internal consistency of FFQ has been determined at Cronbach's alpha of $89 \%$.

BFI consists of 10 items, and the first question determines whether the respondent has experienced unusual fatigue over the past week. Within a score range of $0-10$, other items in BFI measure the level of current fatigue, general fatigue over the past 24 hours, highest level of fatigue over the past 24 hours, effects of fatigue on general activities over the past 24 hours, mood, ability to walk, communication with others, and enjoying life.

Scores in BFI are as follows: No fatigue $=$ zero, mild fatigue $=0-3$, average fatigue $=4-6$, severe fatigue $=7-9$, and very severe fatigue $=10$. Reliability and validity of this questionnaire have been confirmed in previous studies, with Cronbach's alpha estimated at $93 \%(21-24)$.

\section{Data collection}

After the approval of the study protocol by the Ethics Committee of Tarbiat Modares University, the researcher referred to the oncology and radiotherapy/ chemotherapy departments of Imam Reza Hospital of Kermanshah and selected the candidates. Participants of the experimental and control groups completed a demographic questionnaire, BFI, and FFQ. In addition, participants of the experimental group completed Orem's self-care form designed for CRC patients. Based on the collected data, self-care capabilities and needs of CRC patients, including self-care desire, awareness, and skills, were measured, and limitations of each patient were determined as well.

Afterward, the researcher listed the diagnosis results, determined the objectives of the study, and designed the healthcare intervention based on the study objectives. Intervention for the experimental group encompassed training, supporting, and coaching, which consisted of three stages based on Orem's self-care model (five training sessions). The training sessions were focused on different aspects, including nutrition, fatigue reduction techniques, sleep quality improvement, phone/face-to-face follow-up, and checklist evaluation of available CRC patients in the clinic.

In this study, Orem's nursing process was described in three steps. Initially, we determined the nursing care needs of the subjects, and following that, a system was designed for the standard process of nursing care accordingly. In the third step, nursing activities that were implemented by nurses were evaluated. Nurses assessment Self care in the field of nutrition and Fatigue.Orem's selfcare model, nurses with nursing history form using information from patients (25). Nursing history contributes to determining patient needs in terms of self-management and self-care abilities. In addition, In addition, this causes the patient care program to be developed based on the patient's treatment needsThe main self-care needs in this regard include taking care of all the needs of patients, care needs in terms of self-development, In case of deviation of Health (25-27).

For the intervention, the designed self-care program was implemented based on self-care training and objectives, focusing on aspects such as proper nutrition, physical activities, and muscle relaxation techniques.

In the experimental group, training intervention consisted of three stages and was implemented in five sessions based on Orem's self-care model. Intervention stages included patient training on CRC and its treatments, proper nutrition status, fatigue reduction methods, and techniques to improve sleep quality. The first session of self-care education was focused on self-care training, and the educational content included an introduction to the physiology of digestion system and causes of CRC, available treatments, and the associated complications of CRC treatments.

The first session was held for five groups of 
patients (seven subjects in each group) through group discussion for 60 minutes. At the end of the first session, participants were asked different questions in order to evaluate and record the results. The second session was focused on proper nutrition and cooking techniques suitable for CRC patients. Due to the variable dietary habits of the subjects, this session was held privately for each subject in the presence of a family member.

The third session was focused on information about fatigue, causes of fatigue, and exercise techniques (warming up, walking, and cool-down activities), which was held for 20 minutes three times a week. Considering that pain and low quality of life are among the main causes of fatigue, participants were informed on non-medicinal methods of pain relief during the fourth session of intervention (e.g., music therapy and distraction). This session was held for five CRC patient groups (seven subjects in each group) through lectures and displaying therapeutic techniques and educational films.

The last session of the intervention was focused on the methods of fatigue reduction, improvement of sleep quality, and progressive muscle relaxation techniques (45-60 minutes). This session was held privately for each patient in the presence of a family member through lectures and displaying educational films in order to facilitate learning. At the end of each session, self-care checklists of the educational content were collected and evaluated.

After the intervention, participants were followedup via phone contact, face-to-face meetings, contact with family members, and review of the checklists that were completed by the patients at the clinic.

Along with the training sessions, the researcher applied supportive techniques, such as motivating the patients to adhere to their diet, reasoning with the patients, and offering mental support. To this end, contact information of the researcher was provided for the patients and their family members in case of enquiries. All the training sessions were held in the presence of one family member to assure mental support and that the patient would fully comply with the self-care program.

Two months after the intervention, patients were asked to complete the self-care questionnaire for
CRC patients. In this study, subjects of the control group received routine care.

\section{Statistical analysis}

Data analysis was performed in SPSS version 16 using descriptive (mean, frequency, and frequency percentage) and inferential statistics (Chi-square for qualitative variables and independent T-test for quantitative variables). To verify the normal distribution of data, we used the KolmogorovSmirnov test. In addition, Mann-Whitney U test and Wilcoxon test were used to assess and compare the quantitative variables between the two groups. In this study, $\mathrm{P}$ value of less than 0.05 was considered statistically significant.

\section{Results}

Participants of this study were within the age range of 40-70 years, and mean age of the subjects in the experimental and control groups was $54 \pm 7.61$ and $54 \pm 7.89$ years, respectively. In terms of marital status, the majority of participants in the experimental group $(65.7 \% ; n=23)$ and control group $(62.9 \% ; n=22)$ were married. Results of Chisquare and independent $\mathrm{T}$-test showed no significant differences between the two groups in terms of demographic characteristics (Table 1).

Our findings were indicative of no significant differences between the experimental and control groups in terms of nutrition status before the intervention, including bread and cereals $(P=0.381)$, proteins $(P=0.446)$, dairy products $(P=0.85)$, fruits $(P=0.777)$, and vegetables $(P=0.459)$. However, results of Wilcoxon test after the intervention were suggestive of changes in the nutritional behaviors of the experimental group, which was attributed to the implementation of Orem's self-care model.

In this regard, results of Mann-Whitney U test were indicative of significant differences between the nutrition status of the experimental and control groups after the intervention, including bread and cereals $(P=0.253)$, proteins $(P=0.07)$, dairy products $(P=0.001)$, fruits $(P=0.002)$, and vegetables $(P=0.001)$.

With respect to the variable of fatigue in CRC 
Table 1. Demographic characteristics of participants in experimental and control groups

\begin{tabular}{|c|c|c|c|c|c|c|}
\hline \multirow{2}{*}{ Variables } & \multirow{2}{*}{ Groups } & \multicolumn{2}{|c|}{ Experiment group } & \multicolumn{2}{|c|}{ Control group } & \multirow[t]{2}{*}{ Sig. } \\
\hline & & $\mathrm{N}=35$ & N\% & $\mathbf{N}=\mathbf{3 5}$ & $\mathbf{N} \%$ & \\
\hline \multirow{3}{*}{ Education } & Below high school diploma & 22 & 62.9 & 20 & 57.1 & \multirow{3}{*}{$\begin{array}{l}P=0.49 \\
\chi^{2}=0.46\end{array}$} \\
\hline & High school diploma & 9 & 25.7 & 10 & 28.6 & \\
\hline & Above high school diploma & 4 & 11.4 & 5 & 14.3 & \\
\hline \multirow{2}{*}{ Income } & Low & 23 & 65.7 & 24 & 68.57 & \multirow{2}{*}{$\begin{array}{l}P=0.79 \\
\chi^{2}=0.06\end{array}$} \\
\hline & Average & 12 & 34.3 & 11 & 31.43 & \\
\hline \multirow{2}{*}{ Disease record in the family } & yes & 14 & 40 & 16 & 45.72 & \multirow{2}{*}{$\begin{array}{c}\mathrm{P}=0.62 \\
\chi^{2}=0.23\end{array}$} \\
\hline & No & 21 & 60 & 19 & 54.28 & \\
\hline \multirow{2}{*}{ Record of intestine polyp } & yes & 6 & 17.1 & 8 & 22.9 & \multirow{2}{*}{$\begin{array}{l}P=0.55 \\
\chi^{2}=0.35\end{array}$} \\
\hline & No & 29 & 82.9 & 27 & 77.1 & \\
\hline \multirow{3}{*}{ Diagnosed for } & 1 year & 18 & 51.43 & 18 & 51.43 & \multirow{3}{*}{$\begin{array}{c}\mathrm{P}=0.53 \\
\mathrm{t}=-0.6\end{array}$} \\
\hline & 2 years & 12 & 34.28 & 10 & 28.57 & \\
\hline & 3 years & 5 & 14.29 & 7 & 20 & \\
\hline \multirow{2}{*}{ Smoking record } & yes & 17 & 48.6 & 15 & 42.9 & \multirow{2}{*}{$\begin{array}{l}P=0.63 \\
\chi^{2}=0.23\end{array}$} \\
\hline & No & 18 & 51.4 & 20 & 57.1 & \\
\hline \multirow{2}{*}{ Diet } & yes & 8 & 22.85 & 7 & 20 & \multirow{2}{*}{$\begin{aligned} P & =0.77 \\
\chi^{2} & =0.085\end{aligned}$} \\
\hline & No & 27 & 77.15 & 28 & 80 & \\
\hline \multirow{2}{*}{ Physical activities } & yes & 8 & 22.85 & 5 & 14.29 & \\
\hline & No & 27 & 77.15 & 30 & 85.71 & \\
\hline \multirow{3}{*}{ Cancer } & Colon & 26 & 74.3 & 27 & 77.1 & \multirow{3}{*}{$\begin{array}{l}P=0.92 \\
\chi^{2}=0.16\end{array}$} \\
\hline & Rectum & 5 & 14.3 & 5 & 14.3 & \\
\hline & Colorectal & 4 & 11.4 & 3 & 8.6 & \\
\hline \multirow{2}{*}{ Treatment } & Chemotherapy & 23 & 65.7 & 22 & 62.9 & \multirow{2}{*}{$\begin{array}{c}\mathrm{P}=0.8 \\
\chi^{2}=0.062\end{array}$} \\
\hline & Radiotherapy & 12 & $34 / 3$ & 13 & 37.1 & \\
\hline
\end{tabular}

Table 2. Average portion of bread and cereals, proteins, dairy products, and fruits and vegetables in diet of experimental and control groups before intervention and two months after intervention

\begin{tabular}{|c|c|c|c|c|c|c|}
\hline Variable & Stage & $\begin{array}{c}\text { Experimental } \\
\text { group } \\
(\mathrm{Mean} \pm \mathrm{SD})\end{array}$ & $\begin{array}{c}\text { Control group } \\
(\text { Mean } \pm \text { SD) }\end{array}$ & $\begin{array}{c}\text { Mann-Whitney } \\
\text { U test }\end{array}$ & $\begin{array}{l}\text { Wilcoxon test } \\
\text { Experimental } \\
\text { group Before } \\
\text { and after test }\end{array}$ & $\begin{array}{l}\text { Wilcoxon test } \\
\text { control group Before } \\
\text { and after test }\end{array}$ \\
\hline \multirow{2}{*}{ Bread and cereals } & Before intervention & $0.796 \pm 2.11$ & $0.718 \pm 2.11$ & $\begin{array}{l}P=0.38 \\
Z=2.45\end{array}$ & \multirow{2}{*}{$P=0.002$} & \multirow{2}{*}{$P=0.28$} \\
\hline & After intervention & $0.808 \pm 2.37$ & $0.802 \pm 2.06$ & $\begin{array}{c}P=0.253 \\
\mathrm{z}=1.43\end{array}$ & & \\
\hline \multirow{2}{*}{ Proteins } & Before intervention & $1.89 \pm 0.867$ & $1.89 \pm 0.932$ & $P=0.446$ & \multirow{2}{*}{$P=0.024$} & \multirow{2}{*}{$P=0.56$} \\
\hline & After intervention & $2.34 \pm 0.873$ & $1.86 \pm 0.912$ & $\begin{array}{l}P=0.07 \\
\mathrm{z}=1.65\end{array}$ & & \\
\hline \multirow[b]{2}{*}{ Dairy products } & Before intervention & $1.77 \pm 0.902$ & $1.89 \pm 0.900$ & $P=0.85$ & \multirow[b]{2}{*}{$P=0.001$} & \multirow[b]{2}{*}{$P=0.142$} \\
\hline & After intervention & $2.87 \pm 0.877$ & $1.83 \pm 0.923$ & $\begin{aligned} P & =0.001 \\
\mathrm{z} & =3.37\end{aligned}$ & & \\
\hline \multirow{2}{*}{ Fruits } & Before intervention & $1.60 \pm 0.881$ & $1.46 \pm 0.870$ & $P=0.777$ & \multirow{2}{*}{$P=0.001$} & \multirow{2}{*}{$P=0.31$} \\
\hline & After intervention & $2.17 \pm 0.923$ & $1.51 \pm 0.818$ & $\begin{array}{c}P=0.002 \\
\mathrm{z}=3.13\end{array}$ & & \\
\hline \multirow[b]{2}{*}{ Vegetables } & Before intervention & $1.63 \pm 0.843$ & $1.46 \pm 0.780$ & $P=0.459$ & \multirow[b]{2}{*}{$P=0.001$} & \multirow[b]{2}{*}{$P=0.08$} \\
\hline & After intervention & $2.14 \pm 0.944$ & $1.60 \pm 0.847$ & $\begin{array}{c}P=0.001 \\
\mathrm{z}=4.26\end{array}$ & & \\
\hline
\end{tabular}


Table 3. Mean general fatigue, current fatigue, usual fatigue, and highest fatigue level over 24 hours in experimental and control groups based on Orem's self-care model

\begin{tabular}{|c|c|c|c|c|c|c|c|}
\hline \multirow{3}{*}{$\begin{array}{l}\text { Group } \\
\text { Fatigue }\end{array}$} & \multicolumn{2}{|c|}{ Experimental group } & \multicolumn{2}{|c|}{ Control group } & \multirow{3}{*}{$\begin{array}{l}\text { Mann-Whitney } \\
\text { U test }\end{array}$} & \multirow{3}{*}{$\begin{array}{c}\text { Wilcoxon test } \\
\text { Experimental group } \\
\text { Before and after test }\end{array}$} & \multirow{3}{*}{$\begin{array}{l}\text { Wilcoxon test } \\
\text { control group Before } \\
\text { and after test }\end{array}$} \\
\hline & $\begin{array}{c}\text { Before } \\
\text { intervention }\end{array}$ & $\begin{array}{c}\text { After } \\
\text { intervention }\end{array}$ & $\begin{array}{c}\text { Before } \\
\text { intervention }\end{array}$ & $\begin{array}{c}\text { After } \\
\text { intervention }\end{array}$ & & & \\
\hline & Mean \pm SD & Mean \pm SD & Mean \pm SD & Mean \pm SD & & & \\
\hline $\begin{array}{l}\text { Fatigue over past } 24 \\
\text { hours }\end{array}$ & $2.67 \pm 4.65$ & $2.53 \pm 2.6$ & $2.46 \pm 4.94$ & $2.58 \pm 4.74$ & $\begin{array}{c}P=0.722 \text { (before) } \\
P=0.002 \text { (after) } \\
\mathrm{z}=2.35\end{array}$ & $P=0.001$ & $P=0.85$ \\
\hline $\begin{array}{l}\text { Average fatigue over } \\
\text { past } 24 \text { hours }\end{array}$ & $2.44 \pm 3.82$ & $2.34 \pm 1.97$ & $2.85 \pm 4.57$ & $1.93 \pm 5.29$ & $\begin{array}{c}P=0.359 \text { (before) } \\
P=0.006 \text { (after) } \\
\mathrm{z}=3.15\end{array}$ & $P=0.0001$ & $P=0.102$ \\
\hline $\begin{array}{l}\text { Highest level of } \\
\text { fatigue over past } 24 \\
\text { hours }\end{array}$ & $2.32 \pm 4.72$ & $2.22 \pm 1.82$ & $2.54 \pm 4.86$ & $2.65 \pm 4.92$ & $\begin{array}{c}P=0.981 \text { (before) } \\
P=0.018 \text { (after) } \\
\mathrm{z}=1.89\end{array}$ & $P=0.001$ & $P=0.194$ \\
\hline General fatigue & $2.76 \pm 4.58$ & $2.7 \pm 3.97$ & $2.007 \pm 5.31$ & $3.05 \pm 4.82$ & $\begin{array}{c}P=0.602 \text { (before) } \\
P=0.001 \text { (after) } \\
\mathrm{z}=3.77\end{array}$ & $P=0.0001$ & $P=0.07$ \\
\hline activity General & $3.03 \pm 4.4$ & $2.38 \pm 2.34$ & $2.8 \pm 4.34$ & $2.9 \pm 4.42$ & $\begin{array}{c}P=0.83 \text { (before) } \\
P=0.015 \text { (after) } \\
\text { F=2.59 }\end{array}$ & $P=0.0001$ & $P=0.329$ \\
\hline $\begin{array}{l}\text { Effect of fatigue on } \\
\text { mood }\end{array}$ & $3.31 \pm 4.25$ & $2.53 \pm 2.17$ & $3.25 \pm 3.94$ & $3.10 \pm 4$ & $\begin{array}{c}P=0.67 \text { (before) } \\
P=0.025 \text { (after) } \\
\mathrm{F}=3.43\end{array}$ & $P=0.002$ & $P=0.69$ \\
\hline Ability to walk & $2.89 \pm 5.17$ & $2.82 \pm 3.25$ & $3.13 \pm 5.28$ & $3.26 \pm 5$ & $\begin{array}{c}P=0.86 \text { (before) } \\
P=0.03 \text { (after) } \\
\mathrm{z}=1.89\end{array}$ & $P=0.0001$ & $P=0.102$ \\
\hline $\begin{array}{l}\text { Communication with } \\
\text { others }\end{array}$ & $3.02 \pm 4.02$ & $3.32 \pm 2.28$ & $3.14 \pm 4.62$ & $2.87 \pm 4.44$ & $\begin{array}{c}P=0.46 \text { (before) } \\
P=0.04 \text { (after) } \\
\mathrm{z}=4.11\end{array}$ & $P=0.739$ & $P=0.0001$ \\
\hline Enjoying life & $3.17 \pm 5.14$ & $2.65 \pm 2.40$ & $2.97 \pm 4.02$ & $2.98 \pm 3.94$ & $\begin{array}{c}P=0.58 \text { (before) } \\
P=0.035 \text { (after) } \\
\mathrm{z}=3.47\end{array}$ & $P=0.0001$ & $P=0.06$ \\
\hline
\end{tabular}

patients, our findings were indicative of significant differences between the experimental and control groups after the intervention in terms of current fatigue, highest level of fatigue $(P=0.018)$, fatigue over the past 24 hours, effects of fatigue on the mood over the past 24 hours $(P=0.025)$, daily activities $(P=0.015)$, ability to walk $(P=0.03)$, communication with others $(P=0.04)$, and enjoying life $(P=0.035)$.

According to the results of this study, use of a self-care program proved to be beneficial for CRC patients. Moreover, results of Wilcoxon test were indicative of no significant difference before and after the intervention.in subjects of the control group in terms of general fatigue $(P=0.194)$. In addition, the same results revealed significant changes in the general fatigue of participants after the intervention in the experimental group $(P=0.0001)$ (Table 3$)$.

\section{Discussion}

The present study aimed to investigate the effects of Orem's self-care model on the fatigue and nutrition status of patients diagnosed with CRC. According to the findings, Orem's self-care model improved the nutrition status of CRC patients in food groups of dairy products and fruits and vegetables, and it reduced the fatigue of these patients as well.

Furthermore, results of the current study were indicative of increased intake of bread and cereals in the daily diet of the subjects in the experimental group, so that bread and cereals model approached the standard level. This finding is in congruence with the studies by Pasdar (28) and Pourfarzi (29), while inconsistent with the findings of Aysha. This discrepancy could be due to the variations in the nutritional culture of different regions in Iran and other countries (30).

As for the category of proteins, dietary habits of the majority of CRC patients in the present study was lacking in proteins, and despite emphasis on the necessity of adequate protein intake for these patients, no significant difference was observed between the control and experimental groups before 
and after the intervention in this regard. This is consistent with the findings of Lopes (31) and Dehganzadeh (32), which could be due to the fact that high-protein foods are relatively expensive, and the majority of CRC patients in our study were coming from low-income families. Our findings showed a significant difference between dietary protein intake and income status of the participants in both study groups before and after the intervention.

Considering the effect of calcium on tumor control, milk and other dairy products are inherent to the diet of patients with digestive cancers. In the current study, consumption of milk and other dairy products was below the standard level in the control and experimental groups before the intervention, which is in line with the studies by Aysha and Pasdar et al. $(28,30)$. However, subjects of the experimental group reported increased intake of milk and other dairy products in their diet after the intervention, which was mainly attributed to the implemented training and self-care capacity of the patients.

With regard to the category of fruits and vegetables, our participants in both study groups had inadequate dietary intake of fruits and vegetables before the intervention, which is consistent with the results obtained by Aysha and Lopes (30, 31). For many reasons, fruits and vegetables are important dietary ingredients for CRC patients since these nutrients are abundant sources of antioxidants and different vitamins, which are essential to preventing tumor recurrence.

Furthermore, specific medicines used in chemotherapy protocols might lead to complications such as flatulence, constipation and dehydration, and consumption of fruits and vegetables largely contributes to the reduction of constipation and flatulence. In the present study, patients of the experimental group reported increased intake of fruits and vegetables in their diet after the training intervention (28).

With respect to fat consumption, the majority of our patients used 8-11 units of fat in their diet before the intervention. To reduce fat consumption, participants of the experimental group received training on the reduction of fat intake, as well as the advantages of herbal oils, and after the implementation of the self-care program, they reported reduced fat consumption in their diet.

Another objective of the present study was to evaluate the fatigue of CRC patients and reduce this variable in the experimental group. According to our findings, participants in the experimental and control groups had a significant difference in this regard before the intervention. However, fatigue level reduced in patients of the experimental group after the intervention, which confirms the effectiveness of Orem's self-care model in controlling fatigue.

Our findings were suggestive of a significant association between the level of fatigue and lack of sufficient sleep in CRC patients. To reduce fatigue and compensate for sleep deprivation, we implemented routine exercise programs and progressive muscle relaxation techniques, while balancing rest and activity in the patients. Fatigue and sleep deprivation were observed to decrease in CRC patients through improving self-care awareness, skills, and capabilities. Moreover, use of muscle relaxation techniques proved to be effective in relieving mental and physical pressure through alleviating muscle tension, weariness and fatigue.

In a study, Pizarro et al. reported that progressive muscle relaxation improved sleep quality and reduced fatigue in patients (33). In the present study, development of self-care program of progressive muscle relaxation was used to reduce fatigue and improve sleep quality in patients in the experimental group. Furthermore, our findings denoted an association between routine physical exercise, fatigue, and quality of sleep in CRC patients of the experimental group. In other words, routine exercise was found to reduce the fatigue of CRC patients in the experimental group.

In another research, Mock et al. reported that fatigue of patients in the experimental group reduced after the implementation of an exercise program, so that there was a significant difference between the level of fatigue before and after the intervention (34).

Consistent with our findings, Rad et al. stated that fatigue of the majority of patients in the experimental group (56\%) was at an average level before the intervention and it decreased significantly after the 
implementation of a physical exercise program. This confirms the positive effects of physical exercise planning on the reduction of fatigue in chronic patients (35).

Similarly, the results obtained by Cheville et al. showed that after eight weeks of physical exercise plan, fatigue of the patients decreased and sleep quality enhanced in the subjects (17). It could be inferred that in the mentioned study, application of Orem's self-care model could effectively improve the awareness of patients, resulting in increased sleep quality and decreased fatigue.

Consistent with the study by Hoseini (36), other findings were suggestive of the difference between the severity of nausea and vomiting before and after the intervention. In this regard, Piamjariyakul et al. reported that $73 \%$ and $61 \%$ of the patients had self-care disorders in the areas of nutrition and oral health, respectively. Among these patients, 5\% had nausea and vomiting, 58\% suffered from fatigue, and $50 \%$ had constipation. Findings of the mentioned study revealed a direct correlation between nutritional disorders, nausea and vomiting, and lack of oral hygiene (37), so that patients undergoing chemotherapy and radiotherapy required self-care training on nutrition, nausea and vomiting, and fatigue.

According to the results of the current study, selfcare awareness of CRC patients in the experimental group was relatively low before the intervention, and a significant improvement was observed in this variable after the implementation of Orem's self-care model. Similarly, Oshvandi and Taghdisi reported increased scores of self-care awareness, desire, skills, and capabilities among the studied patients $(38,39)$.

Some of the limitations of the present study were the psychological characteristics of CRC patients, economic problems of the patients, and differences in the motivation and interests of the participants.

In the current study, we aimed to clarify whether the application of Orem's self-care theory could influence the nutrition status and severity of fatigue in patients diagnosed with CRC. According to the results, this behavioral model could improve nutrition status and reduce fatigue in CRC patients.

\section{Conclusion}

According to the results of this study, implementation of a training program based on Orem's self-care theory could enhance the clinical condition of patients diagnosed with CRC. Furthermore, a significant improvement was observed in the self-care capabilities of the participants after the training intervention. Owing to the fact that the main purpose of clinical nursing is to provide care services for patients to improve their conditions, proper patient education is of paramount importance. Therefore, it is recommended that oncology nurses adhere to Orem's self-care model in order to raise the quality of nutrition and diminish the level of fatigue in cancer patients.

\section{Conflicts of interest}

None declared.

\section{Authors' contributions}

All authors contributed equally to the writing of the scientific proposal, data collection, and manuscript drafting. The final manuscript was reviewed and approved by all the authors.

\section{Acknowledgements}

This article is extracted from Master's Thesis Nursing in the I Department of Tarbiat Modares University of Tehran, Iran (No. 30/31259). Hereby, we extend our gratitude to the Vice Chancellor of the Research Department, Faculty of Nursing and Midwifery, and Faculty of Medical Sciences of Tarbiat Modares University of Tehran for assisting us in this research project. We would also like to thank the personnel of Imam Reza Hospital of Kermanshah, Iran and all the patients who cooperated in this study.

\section{References}

1. Pourhoseingholi MA, Hajizadeh EB, Abadi A, Safaee A, Moghimi D, Zali MR. Comparing cox regression and parametric models for survival analysis of patients with 
gastric cancer. Iran J Epidemiol 2007; 3(1):25-9 (Persian).

2. Bollschweiler E, Wolfgarten E, Nowroth T, Rosendahl $\mathrm{U}$, Moing SP, Holscher AH. Vitamin intake and risk of subtypes of esophageal cancer in Germany. J Cancer Res Clin Oncol 2002; 128(10):575-80.

3. Mousavi SM, Gouya MM, Ramazani R, Davanlou M, Hajsadeghi N, Seddighi Z. Cancer incidence and mortality in Iran. Ann Oncol 2009; 20(3):556-63 (Persian).

4. Azadeh S, Moghimi-Dehkordi B, Fatemi SR, Pourhoseingholi MA, Ghiasi S, Zali MR. Colorectal Cancer in Iran: an epidemiological study. Asian Pac J Cancer Prev 2008; 9(1):123-6.

5. Aaltonen LA, Salovaara R, Kristo P, Canzian F, Hemminki A, Peltomäki P, et al. Incidence of hereditary nonpolyposis colorectal cancer and the feasibility of molecular screening for the disease. N Engl J Med 1998; 338(21):1481-7.

6. Alidina A, Gaffar A, Hussain F, Islam M, Vaziri I, Burney I, et al. Survival data and prognostic factors seen in Pakistani patients with esophageal cancer. Ann Oncol 2004; 15(1):118-22.

7. Kahi CJ, Rex DK, Imperiale TF. Screening, surveillance, and primary prevention for colorectal cancer: a review of the recent literature. Gastroenterology 2008; 135(2):380-99.

8. Zhang Q, Sha S, Xu B, Liang S, Wu K. Prevalence of colorectal cancer in patients with ulcerative colitis: a retrospective, monocenter study in China. J Cancer Res Ther 2015; 11(4):899-903.

9. Billiard M. Fatigue et troubles du sommeil chez les patients atteints de cancer colorectal. Pathol Biol 2013; 61(5):83-7.

10. Bingham SA, Luben R, Welch A, Wareham N, Khaw KT, Day N. Are imprecise methods obscuring a relation between fat and breast cancer? Lancet 2003; 362(9379):212-4.

11. Richardson J, Smith JE, McCall G, Richardson A, Pilkington K, Kirsch I. Hypnosis for nausea and vomiting in cancer chemotherapy: a systematic review of the research evidence. Eur J Cancer Care 2007; 16(5):402-12.

12. Geden EA, Taylor SG. Theoretical and empirical description of adult couples' collaborative self-care systems. Nurs Sci Q 1999; 12(4):329-34.

13. Rehill S. Conceptual models for nursing practice. $3^{\text {rd }}$ ed. California: Norwalk Appleton and Lange; 1989. P. 369.

14. Horsburgh ME. Self-care of well adult Canadians and adult Canadians with end stage renal disease. Int J Nurs Stud 1999; 36(6):443-53.

15. Ricka R, Vanrenterghem Y, Evers GC. Adequate self-care of dialysed patients: a review of the literature. Int J Nurs Stud 2002; 39(3):329-39.

16. Abootalebi G, Vosooghi N, Mohammad Nejad E, Namadi M, Akbari Kaji M. Study of the self-care agency in patients with heart failure. Iran J Crit Care Nurs 2012; 4(1):203-8 (Persian).

17. Cheville AL, Kollasch J, Vandenberg J, Shen T, Grothey A, Gamble G, et al. A home-based exercise program to improve function, fatigue, and sleep quality in patients with Stage IV lung and colorectal cancer: a randomized controlled trial. J Pain Symptom Manage 2013; 45(5):811-21.

18. Zarief Yeganeh M, Eghtesadi S, Vakili M, Faghih A, Haghani H, Noormohammadi I, et al. Nutritional assessment of cancer patients during chemotherapy in Iran University of medical sciences affiliated hospitals, 2006-2007. Razi J Med Sci 2009; 16(65):25-39 (Persian).

19. Hosseini Eafahani F, Asghari G, Mirmiran P, Azizi F. Reproducibility and relative validity of food group intake in a food frequency questionnaire developed for the Tehran Lipid and Glucose Study. J Epidemiol 2010; 20(2):150-8 (Persian).

20. Mirmiran P, Hosseini Esfahani F, Mehrabi Y, Hedayati M, Azizi F. Reliability and relative validity of an FFQ for nutrients in the Tehran Lipid and Glucose Study. Public Health Nutr 2010; 13(5):654-62 (Persian).

21. Mendoza TR, Wang XS, Cleeland CS, Morrissey M, Johnson BA, Wendt JK, et al. The rapid assessment of fatigue severity in cancer patients: use of the brief fatigue inventory. Cancer 1999; 85(5):1186-96.

22. Escalante CP, Meyers C, Reuben JM, Wang X, Qiao W, Manzullo E, et al. A randomized, double-blind, 2-period, placebo-controlled crossover trial of a sustained-release methylphenidate in the treatment of fatigue in cancer patients. Cancer J 2014; 20(1):8-14.

23. Davodi A, Anoosheh M, Memarian R. The effect of self-care education on quality of life in patients with esophageal cancer following esophagectomy. ZUMS J 2007; 15(58):57-65.

24. Sternberg CN, Molina A, North S, Mainwaring P, Fizazi $\mathrm{K}$, Hao Y, et al. Effect of abiraterone acetate on fatigue in patients with metastatic castration-resistant prostate cancer after docetaxel chemotherapy. Ann Oncol 2013; 24(4):1017-25.

25. Memarian R. Application of nursing concepts and theories. $1^{\text {st }}$ ed. Tehran: Tarbiat Modarres University; 2012 (Persian).

26. Mohammadpor A, Rahmati Sharghi N, Khosravan S, Alami A. Investigating the level of self-care and supportiv eeducative needs of patients with myocardial infarction, based on Orem's model. J Res Health 2013; 3(4):489-96 (Persian).

27. Aghakhani N, Sharif F, Sharifnia H, Rahbar N, Parkhashjo M, Amami Zeydi A, et al. Study of orem's nursing theory effects on nutritional program self-care on quality of life in hemodialysis patients referred in educational hospitals in Urmia-Iran. Fam Health 2012; 1(2):47-54 (Persian).

28. Pasdar Y, Rezaie M, Darbandi M, Mohamadi N, Niazi P. Dietary pattern and food consumption among Kermanshah households, Iran, 2011. J Kerman Univ Med Sci 2014; 21(1):25-36 (Persian).

29. Pourfarzi F, Yazdanbod A, Daneshvar R, Saberi SH. Evaluation of effective factors in incidence of colorectal cancer. J Ardabil Univ Med Sci 2012; 12(5):56-64 (Persian).

30. Alharbi AM. The effect of chemotherapy on nutritional status of breast cancer patients. [Doctore Dissertation]. Riyadh, Saudi 
Arabia: Community Health Sciences at the College of Applied Medical Sciences King Saud University; 2004.

31. Lopes JP, de Castro Cardoso Pereira PM, dos Reis Baltazar Vicente AF, de Bernardo A, Mesquita MF. Nutritional status assessment in colorectal cancer patients. Nutr Hosp 2013; 28(2):412-8.

32. Dehganzadeh S, Jafaraghai F, Tabari KR. Relationship between demographic characteristics, lifestyle and exposure to stressor events and colorectal cancer. Iran J Nurs Res 2011; 7(24):6-15 (Persian).

33. Leon-Pizarro C, Gich I, Barthe E, Rovirosa A, Farrus B, Casas F, et al. A randomized trial of the effect of training in relaxation and guided imagery techniques in improving psychological and quality-of-life indices for genecologic and breast brachytherapy patients. Psycooncology. 2007; 16(11):971-9.

34. Mock V, Frangakis C, Davidson NE, Ropka ME, Pickett $\mathrm{M}$, Poniatowski B, et al. Exercise manages fatigue during breast cancer treatment: a randomized controlled trial.
Psychooncology 2005; 14(6):464-77.

35. Rad M, Memarian R, Aghili M. The effect of scheduled exercise program on the fathigue of cancer patients under external radiotherapy. J Sabzevar Univ Med Sci 2003; 9(4):13-20 (Persian).

36. Sadat Hoseini AS. Effect of music therapy on chemotherapy nausea and vomiting in children with malignancy. J Hayat 2009; 15(2):5-14 (Persian).

37. Piamjariyakul U, Williams PD, Prapakorn S, Kim M, Park L, Rojjanasrirat W, et al. Cancer therapy-related symptoms and self-care in Thailand. Eur J Oncol Nurs 2010; 14(5):387-94.

38. Oshvandi K, Keshmiri K, Salavati M, Emkanjoo Z, Musavi S. Effectiveness of education based on Orem's self-care model in self-care activity of patients with implantable cardioverter defibrillators. J Hayat 2014; 19(3):47-55 (Persian).

39. Taghdisi MH, Abdi N, Shahsavari S. Health promotion among cancer patients by the problem Based Learning (PBL) method. Health Sys Res 2011; 7(4):434-41 (Persian). 